\title{
Literatura
}

\section{Anillos para soltar a Raưl Zurita en su Paraíso}

Por Anastasio Lovo ${ }^{1}$

\section{RESUMEN}

El escritor Anastasio Lovo arma este texto sobre el poeta chilero Raúl Zurita, a partir del conocimiento de su obra y de la amistas que los une.

Lovo nos entrega en este artículo, algunas claves para la cultura de la trascendental obra Zurita.

Palabras clave: Conocimiento, obra, amistad, clave, cultura, trascendental

\section{I}

Tonocí a Raúl Zurita en el Purgatorio que era Santiago de Chile en el Año del Señor de 1973. Alto, delgado, carilargo de ojos grandes, febriles, morena tez moruna donde aún suenan adufes en lo almendrado. También puedo afirmar -góndola encallada en la laguna de mi recuerdo- a un San Juan de la Cruz de pausada y grave voz enfundado en un abrigo, no se si de alto cuello de tortuga o bufanda a falta de gorguera. Más un tanto de Góngora y tres de Quijote, que sumados a su afición de criar egovacas en AREAS VERDES, lo situaban en bien cumplidos años 22 .

En medio de la noche en la Alameda en la parada de la Católica, Zurita se me acercó y me dijo entusiasta algo así como la empiluchada que en mi texto le había hecho a la poesía de Longone, que él esperaba que sus textos cayeran en manos de alguien que lo empelotara y no en las garras de uno que sólo dijera cojudeces sobre lo que hacía.

Ah, le dije, vos sos Zurita el de las vacas que pastan en áreas verdes regidas y áreas blancas no regidas. Sí me dijo y vos soi el que escribe unas ondas muy cargadas

\begin{abstract}
The writer Anastasio Lovo constructs this text on the Chilean poet Raúl Zurita, from his knowledge of his work and the friendship that unites them.

Lovo gives us in this article, some keys to the culture of the transcendental work of Zurita.

Key Words: knowledge, work, friendship, key, culture, transcendental
\end{abstract}

de metáforas, con un lenguaje barroco que yo creí superado, agotado, que ya no daba pa más en la poesía. Sí le dije desde una fraternidad humana y poética que no me cabe la menor duda aún mutuamente conservamos: el problema Zurita es que vos ya estás cerca de escribir la página en blanco de Mallarmé como poema. Nos reímos al tiempo que abordábamos micro y liebre respectivas en clave de Ciao para disolvernos en la noche.

\section{II}

En 1985, cuando todo Chile era un Gólgota e Il Duce erguía cordilleras muertas, volvía ver a Raúl en una casa de la comuna de Ñuñoa y vi un Raúl traspasado, Raúl doliente, Raúl dolorosa, Raúl rompiéndose de su crisis como equilibrio inestable por dolor, Raúl sufriente a un tris místico de las llagas del Cristo, Raúl crucificadoestragado-estropajo-escupitajo-sanguinolento, Raúl de iterativo tics en la bolsa de sus ojos que desmedían la angustia, que la desbordaban y que a punta de mística se hacia Verbo.

Deleuze con un mazo de mathesis como un demonio al oído me susurraba: "No seás baboso, Raúl Zurita logra su apertura textual a sentidos posibles,

1 Crítico de arte nicaragüense, Coordinador del Área de Cultura de Paz del Instituto "Martin Luther King"-UPOLI. 
mediante la utilización reiterada de una estructura formal susceptible de ser descrita como un par de proposiciones lógicas precedidas y seguidas por un párrafo síntesis de mayor densidad poética que las proposiciones numeradas".

\section{III}

Existe un Narciso en los textos de Zurita. Éste no ocupa únicamente al agua como superficie reflejante, sino a la alteridad del ser -como en el caso de Raquel la prostituta-, a la alteridad de vastos espacios refractantes como el desierto, el mar, la cordillera... como la alteridad poetizable.
Espacios que a través de una implacable y efectiva escritura adquieren categoría metafísica recuperable únicamente en la más alta espiritualidad del yo. Un poderoso yo constituyéndose en un momento de creación de mundo; derrotados y vencidos un yo pecador y un sucio y hediondo mundo.

Textos estos los de Zurita que nos entregan un Brave New World con un extraordinario esplendor, donde todas las relaciones alienantes como la de la madre, la del padre, los hijos, la sociedad, Il Duce, al arribar a un punto mitopoyético de intersección con el yo revelan una nueva escritura que obliga a una nueva lectura donde se fundará la primordial inocencia y un nuevo Paraíso. ¡Manzana y laúd para Zurita. Vino, sal y calavera a su salud!

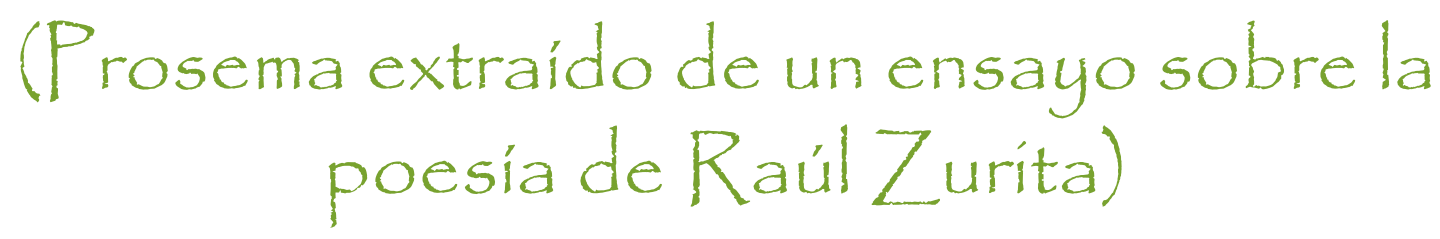

Anastasio Lovo

Jinotepe, 1995- Managua 2010.

Poemas de Raúl Zurita

INRI,

La obsesión de tallar paisajes

\section{Paradero}

En la imagen de Cristo encontramos la reunión de los símbolos absolutos: lo alto y lo bajo, el cielo y la tierra, los cuatro elementos ... La inscripción INRI (Iesus Nazarenus Rex Iudaeórum/ Jesús de Nazaret Rey de los Judíos) representa la burla, la incredulidad, pero también la trascendencia, lo divino, el retorno y la salvación. INRI de Raúl Zurita simboliza este nacimiento nuevo de las almas y los paisajes, el otorgamiento de una identidad permanente para todos esos cuerpos anónimos que fueron arrojados a las fosas comunes de la geografía chilena. A su vez, este poemario representa el cierre de una secuencia en la obra del poeta chileno, y el inicio de algo seguramente insólito. Con todo, INRI es una cumbre que habla por sí misma, un corolario de vistas que se eleva y se suspende más allá de todo lo esperado por la literatura de nuestro tiempo.

Alejandro Tarrab,México 2003

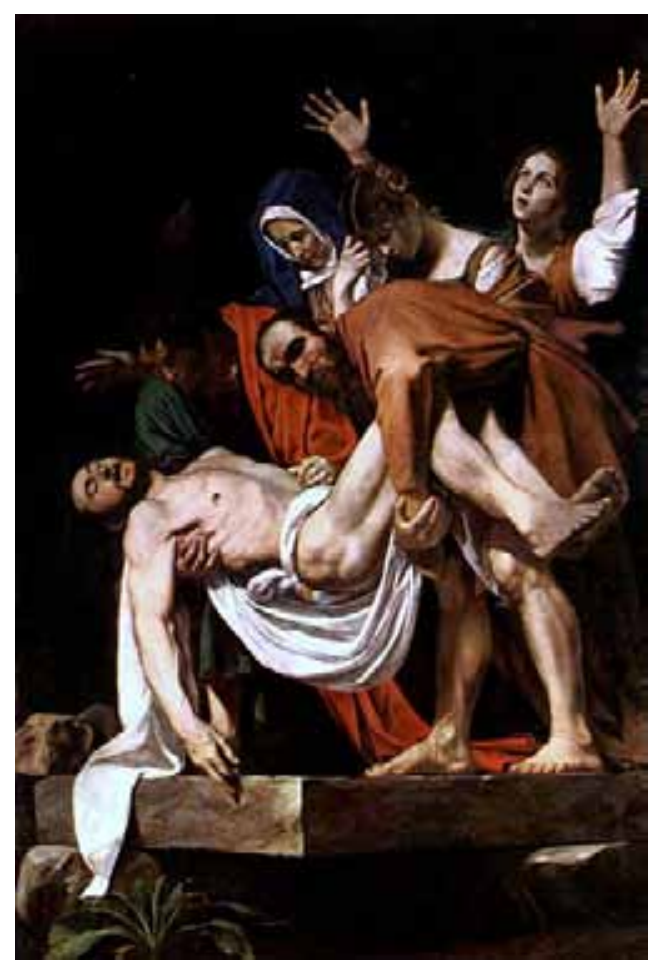




\section{Literatura}

\section{El descenso}

Te palpo, te toco, y las yemas de mis dedos, habituadas a seguir siempre las tuyas, sienten en

la oscuridad que descendemos. Han cortado todos

los puentes y las cordilleras se hunden, el Pacífico

se hunde, y sus restos caen ante nosotros como caen los restos de nuestro corazón. Frente a la muerte alguien nos ha hablado de la resurrección. ¿Significa eso que tus ojos vaciados verán? que mis yemas continuarán palpando las tuyas? Mis dedos tocan en la oscuridad tus dedos y descienden como ahora han descendido las cumbres, el mar, como desciende nuestro amor muerto, nuestras miradas muertas, como estas palabras muertas. Como un campo de margaritas que se doblan te palpo, te toco, y mis manos buscan en la oscuridad la piel de nieve con que quizás reviviremos. Pero no, descendidas, de las cumbres de Los Andes sólo quedan las huellas de estas palabras, de estas páginas muertas, de un campo largo y muerto de flores donde las cordilleras como mortajas blancas, con nosotros debajo y aún abrazados, se hunden.

La línea de la cordillera se desprende del cielo y se hunde, se hunde lentamente, se separa del cielo y se hunde. Es cosa común que las cordilleras se hundan, es cosa común oír las nieves descendiendo, oír las cumbres que se desprenden para abajo. En una tierra enemiga es cosa común oír montañas de cuerpos hundirse boca abajo. Los Andes se hunden en el mar de piedras. Bruno aguarda debajo de las piedras. Susana también aguarda las montañas y montañas de cuerpos debajo de las piedras.

Las heladas montañas se derrumban entre sí mismas y caen. Tal vez el mar las acoja. Hay tal vez un mar donde los cuerpos helados caen. Quizás Zurita eso sea el mar. Un limbo donde los cuerpos caen. Habrán también margaritas. Margaritas en el fondo del mar, en el fondo del mar de piedras. Tal vez las margaritas amen a las heladas montañas. Tal vez los encadenados cuerpos las escuchen gemir. En una tierra enemiga es cosa común que las margaritas giman escuchando caer las cordilleras.

El Pacífico se desprende de la línea de la costa y cae. Fue primero la cordillera y ahora es el mar que cae. Desde la costa hasta el horizonte cae. En una tierra enemiga es cosa común que los cuerpos caigan, que el mar se desprenda de la costa y caiga como las margaritas que gimen escuchando a las cordilleras hundirse donde el amor, donde tal vez el amor Zurita gime llorando porque en una tierra enemiga es cosa común que el Pacífico se derrumbe boca abajo como un torso roto sobre las piedras.

Los Andes son estrellas muertas en el fondo del mar de piedras. El Pacífico también es una estrella muerta en el fondo del mar de piedras. Debajo de las piedras el sepulcro del mar y de las cordilleras es como una noche cuajada de margaritas y estrellas muertas. Las estrellas muertas de Los Andes y del Pacífico se cruzan en el fondo de las piedras. Las margaritas se doblan ante la cruz y gimen. En una tierra enemiga es cosa común que las estrellas formen una cruz sobre nuestras caras muertas.

El océano Pacífico se despegó del horizonte y yace debajo de las piedras, la cordillera de Los Andes también yace. Las piedras cubren las cumbres y el mar como un campo negro. Las margaritas de los campos negros, de la tierra o el agua negra se doblan y gimen sobre las desplomadas montañas, sobre el mar desplomado. En un tierra enemiga es común que el océano y las montañas yazgan bajo las piedras, que el amor yazga, que tu amor yazga Zurita y que sean una tumba tus ojos ciegos abrazándolas.

Las montañas se abrazan en el fondo, el mar es de piedras y se abraza. Quizás las montañas y el mar duermen. En una tierra enemiga es común que los cuerpos se abracen abajo como si durmieran. Campos infinitos de margaritas 


\section{Literatura}

descienden hasta el borde de la playa donde antes estaba el Pacífico. Otros campos lo hacen hasta donde estaban las cordilleras. Las cordilleras y el mar yacen abajo y se abrazan. En una tierra enemiga es cosa común que el mar y las montañas se abracen boca abajo como si durmieran.

Escuchamos caer el mar, las cumbres, las llanuras y eran nuestros cuerpos ciegos los que se derrumbaban amontonándose debajo de las piedras. Las margaritas gimen y tal vez ellas son los dedos que nos palpan tocando en nosotros las vaciadas costas. Quizás es común para las flores. En una tierra enemiga es quizás común que las margaritas se doblen tocándonos en el mar desmoronado. En una tierra enemiga tal vez las margaritas palpen subiendo en sus dedos las montañas.

Están las cordilleras de Los Andes y el Pacífico abrazados debajo de las piedras. Las margaritas crecen en la primavera. Tal vez la primavera crezca. Tal vez las montañas y el océano abrazados se levanten desde debajo de las piedras y sean las margaritas de la nueva primavera. Bruno, Susana, tal vez sus cuerpos se levanten
Desde debajo de las piedras. En una tierra enemiga es cosa común que las margaritas sostengan la nieve que quedó de los caídos cuerpos en la primavera.

Te palpo, te toco, y las yemas de mis dedos buscan las tuyas porque si yo te amo y tú me amas tal vez no todo esté perdido. Las montañas duermen abajo y quizás las margaritas enciendan el campo de flores blancas. Un campo donde Los Andes y el Pacífico abrazados en el fondo de la tierra muerta despierten y sean como un horizonte de flores nuestros ojos ciegos emergiendo en la nueva primavera ¿Será? será así? las margaritas continúan doblándose sobre el mar difunto, sobre las grandes cumbres difuntas y en la oscuridad, descendidos, como dos envanecidas pieles que se buscan, mis dedos palpan a tientas los tuyos porque si yo te toco y tú me tocas tal vez no todo esté perdido y, podamos adivinar algo del amor. De todos los amores muertos que fuimos y de un campo de flores que crecerá cuando nuestras mortajas blancas, cuando nuestras mortajas de nieve de todas las montañas hundidas nos besen boca abajo y nos vuelvan para arriba las erizadas pestañas.

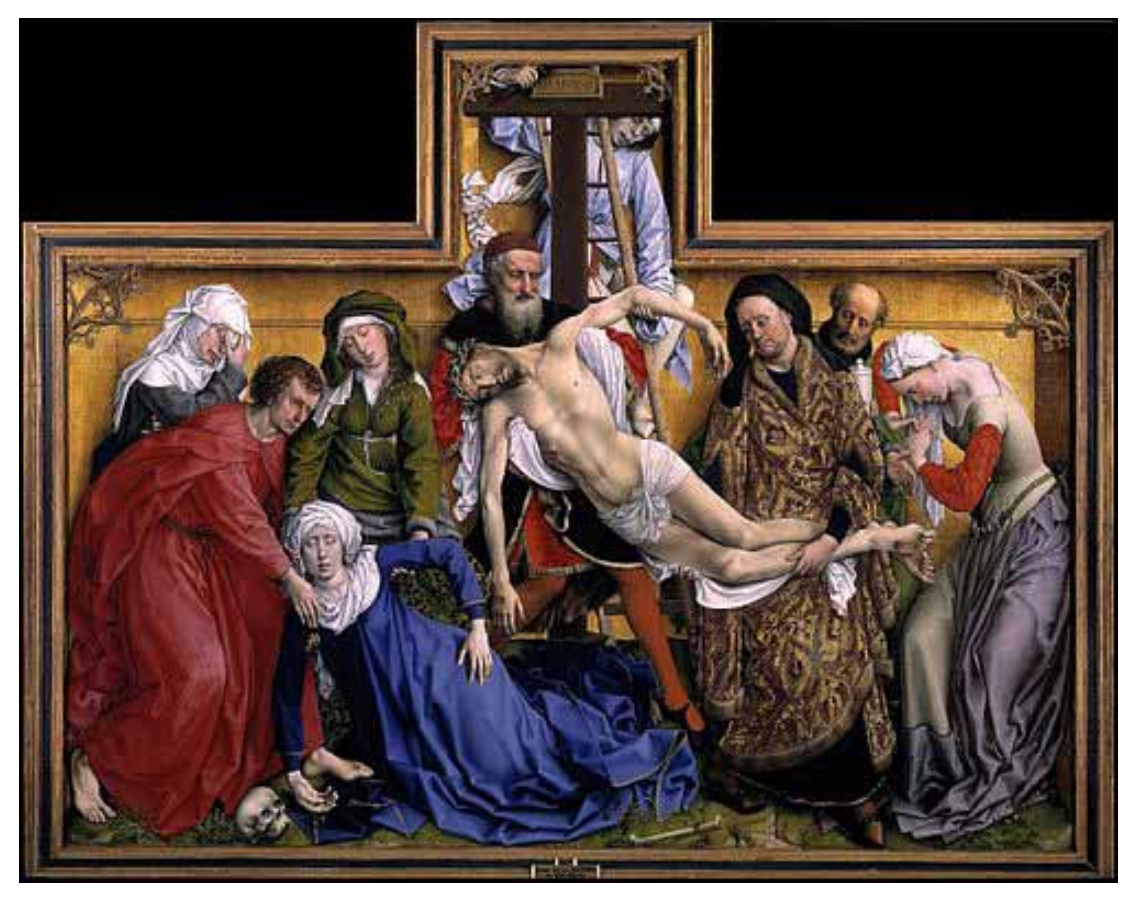

